\title{
Variation of Tocopherol Composition and Morphology in Soybean [Glycine max (L.) Merr.] Germplasms
}

\author{
Young-Jin Kim*, Young-Jin Oh*, Sang-Kyun Cho*, Mi-Ja Lee*, Kwang-Won Lee*, and Kee-Jong Kim** \\ *Department of Rice and Winter Cereal Crops, NICS, RDA, Iksan 570-080, Korea
}

\begin{abstract}
In order to get information on tocopherol content and composition in fifty-six soybean germplasms were evaluated by HPLC. From the principle component analysis, the first three components accounted for $71.6 \%$ of the total variance of tocopherol content in the germplasms. Principal component 1 showed significant correlations with all the morphological markers except 100 -seed weight. Soybean germplasms were divided into three groups by the first two principal components. The highest content of a -tocopherol was $38.6 \mu \mathrm{g}$ per $\mathrm{g}$ in Tanner, while that of $\gamma$ -tocopherol was $195.6 \mu \mathrm{g}$ in PI 91073. In case of $\delta$ -tocopherol, IT 105622 showed the highest value as 29.8 $\mu \mathrm{g}$. The contents of tocopherol were gradually increased from the late August to late September, which was 10 days before maturity, in Alchankong and PI 96322. The tocopherol content was higher in seeds from the plants sown early than those sown late. Total tocopherol contents of PI 96188, Geomjeongkong 2, and Suwon 183 grown in Gimje were higher than those grown in Iksan, but the difference was not observed in PI 96322. These results suggest that the contents of tocopherol in soybean were affected not only by the genotypes but also by environment.
\end{abstract}

Keywords : soybean, principle component, tocopherol content, HPLC

Tocopherols are a class of lipid-soluble antioxidants known collectively as vitamin E, which are essential ingredients in human nutrition (Traber \& Sies, 1996). Vitamin $\mathrm{E}$ is a powerful antioxidants that helps protect cells from the harmful unhealthy oxidative free radicals that can induce potentially damaging by-products of the body's metabolism. Clinical and epidemiological evidences suggest that vitamin E decreases the risk of cancer and cardiovascular and Alzheimer's diseases, promotes immune system and circulatory function, defense against light-induced eye and dermal pathologies, and prevents or slows various chronic degenerative diseases and premature aging (Pryor, 2000; WCRF, 1997). However, obtaining these therapeutic levels of vitamin $\mathrm{E}$ requires daily intake of vitamin $\mathrm{E}$ in excess of the recent Korean recommended daily allowance of $10 \mathrm{mg}$ a-tocopherol (KNS, 2000).

The vitamin $\mathrm{E}$ group consists of $\alpha-, \beta-, \gamma$ - and $\delta$-tocopherols and four corresponding unsaturated derivatives, $\alpha-, \beta-, \gamma-$ and $\delta$-tocotrienols. The four isoforms of tocopherols are synthesized in plants and other photosynthetic organisms. The isoforms differ by the numbers and positions of methyl substitutes on the aromatic head group. Biosynthesis pathway of tocopherol in plant has been studied by Janiszowska \& Pennock (1976) and Hirschberg (1999). Munné-Bosch \& Alegre (2002) reviewed the function of tocopherols and tocotrienols in plants and emphasized advances in research over the last decade.

Seeds and oils of crops, especially soybean oils contain high content of tocopherols and they are good sources of vitamin $\mathrm{E}$ in human diet (Kwon \& Brown, 1984). The major tocopherols found in the seeds and oils are $\gamma$ - and a-tocopherols. The in vivo antioxidant activity of a-tocopherol is higher than that of the other isoforms and vitamin $\mathrm{E}$ activity of a-tocopherol is about 10 -fold higher than that of its precursor $\gamma$-tocopherol (Fukuzawa et al., 1982; KamalEldin \& Appelqvist, 1996). The a- to $\gamma$-tocopherol ratios of soybean, sesame, and corn oils are about $0.09,0.47$, and 0.18 , respectively, indicating composition of tocopherols in major oil crops is nutritionally poor (Sheppard \& Pennington, 1993). The activity of natural-source vitamin E (da-tocopherol) may be up to 100 percent greater than synthetic forms (dla-). Many researchers (Wolfgang, 1976; Carpenter, 1979; Speek et al., 1985) have carried out the analysis of tocopherols in

\footnotetext{
${ }^{\dagger}$ Corresponding author: (Phone) +82-63-840-2107 (E-mail) kkj737@korea.kr

$<$ Received 7 March, 2012; Revised 9 March, 2012; Accepted 13 March, 2012>
} 
oils by the high performance liquid chromatography (HPLC).

This experiment was conducted to get fundamental data required to develop soybean cultivars with high tocopherol contents and to analysis the relationship between the tocopherol contents and the major agronomic characters in the selected groups of soybean germplasms.

\section{MATERIALS AND METHODS}

Fifty-six soybean germplams (21 Korean cultivars, 13 domestics and 22 foreign varieties) were selected among 687 soybean germplams which were cultivated in Iksan. The materials were selected to maximize variation on the bases of the previous morphological and genetic analyses (Kim et al., 1997). To know the effects of the seeding dates and growth locations on tocopherol contents, seeds (PI 96322, Geomjeongkong 2, Suwon 183, PI 96188) were sown in Iksan and Gimje experimental fields of Department of Rice and Winter Cereal Crops, National Institute of Crop Science (NICS) in the late May and June, respectively. Seeds were planted with spacings between rows at $60 \mathrm{~cm}$ and between hills at $15 \mathrm{~cm}$ and $10 \mathrm{~cm}$ in Iksan (May 24) and Gimje (May 26 and June 28), respectively. Three seeds were sown per hill and thinned to one plant 15 days after emergence. The amount of fertilizer applied as basal application was 3,3 and $3.4 \mathrm{~kg} 10 \mathrm{a}^{-1}$ for $\mathrm{N}, \mathrm{P}_{2} \mathrm{O}_{5}$ and $\mathrm{K}_{2} \mathrm{O}$, respectively.

Seeds of soybean germplams grown at NICS and seeds of several varieties harvested at different seed growth stages and locations were used for tocopherol analysis. Freeze-dried seeds were ground under liquid nitrogen into fine powder. The dry sample $(2.5 \mathrm{~g})$ was weighed into a $25 \mathrm{ml}$ volumetric flask. The sample was brought to volume with $1.5 \%$ iso-propyl alcohol in hexane and then vigorously mixed. The mixture was centrifuged at $10,000 \mathrm{rpm}$ and the supernatant was used for tocopherol analysis. The isoforms of tocopherol were separated and determined according to the method of Carpenter (1979) using HPLC (Hitach Co., Japan) equipped with $\mu$-porasil column $(10 \mu \mathrm{m}, 3.9 \mathrm{~mm} \times 300$ $\mathrm{mm}$ ) at room temperature. The UV detector (Hitach Co.) set at $280 \mathrm{~nm}$ was stabilized with mobile phase $(1.5 \%$ iso-propyl alcohol in hexane) at a flow rate of $1 \mathrm{ml} / \mathrm{min}$. Sample injection was made with a $50 \mu \mathrm{l}$ injector. Eluent was detected at $280 \mathrm{~nm}$ and chromatogram was recorded for $20 \mathrm{~min}$. Standards for $a-, \gamma-$ and $\delta$-tocopherol were purchased from Sigma (USA) and the standard for each tocopherol was made up in $1.5 \%$ iso-propyl alcohol in hexane at the concentrations ranging from 50 to $500 \mathrm{ppm}$. The experiment was laid out in a completely randomized design with 3 replications. Principal components analysis (PCA) was used to reduce dimensionality of variability in the germplasms. The scores of calculated variables were used to visualize germplasms in two demensional PCA scatter plots. PCA was performed using SPSS program (SPSS Inc., Chicago, Illinois, USA).

\section{RESULTS AND DISCUSSION}

Table 1 shows the average values of morphological characteristics among 56 soybean germplasms. The traits with higher $\mathrm{CV}$ values have larger genetic variations in the germplasms used.

Eigen values and their contribution percentages obtained from PCA are listed in Table 2. Principal component 1 was composed of 2.57 characters and it contributed $36.7 \%$ of the total variance. The first three major components

Table 1. Average values of agronomic characteristics of 56 soybean germplasms.

\begin{tabular}{lrrrrrr}
\hline \hline Characteristics & Mean & Variance & SD & Minimum & Maximum & CV (\%) \\
\hline Plant height $(\mathrm{cm})$ & 85.9 & 696.1 & 26.4 & 50 & 175 & 30.7 \\
No. of nodes & 17.0 & 15.8 & 4.0 & 10 & 30 & 23.3 \\
No. of branches & 5.6 & 4.4 & 2.1 & 0 & 11 & 36.9 \\
Lodging (0-9) & 3.1 & 4.8 & 2.2 & 0 & 9 & 71.0 \\
Days to flowering & 56.9 & 105.6 & 10.3 & 39 & 86 & 18.0 \\
Days to maturity & 135.7 & 469.8 & 21.7 & 112 & 160 & 15.9 \\
100-seed weight $(\mathrm{g})$ & 22.3 & 92.6 & 9.6 & 8 & 45 & 43.2 \\
\hline
\end{tabular}


Table 2. Eigen values of principal components and their contribution.

\begin{tabular}{lcccccrr}
\hline \hline & \multicolumn{7}{c}{ Principal component (PC) } \\
\cline { 2 - 8 } & PC 1 & PC 2 & PC 3 & PC 4 & PC 5 & PC 6 & PC 7 \\
\hline Eigen value & 2.57 & 1.43 & 1.01 & 0.86 & 0.50 & 0.39 & 0.23 \\
Contribution (\%) & 36.7 & 20.5 & 14.4 & 12.4 & 7.1 & 5.6 & 3.3 \\
Cumulative (\%) & 36.7 & 57.2 & 71.6 & 84.0 & 91.1 & 96.7 & 100 \\
\hline
\end{tabular}

Table 3. Correlation coefficients between agronomic traits and principal component.

\begin{tabular}{lllllc}
\hline \hline \multirow{2}{*}{ Characters } & \multicolumn{5}{c}{ Principal component (PC) } \\
\cline { 2 - 5 } & PC 1 & PC 2 & PC 3 & PC 4 & PC 5 \\
\hline Plant height & $0.859^{* *}$ & -0.205 & -0.020 & 0.111 & $0.307^{*}$ \\
No. of nodes & $0.695^{* *}$ & $-0.570^{* *}$ & -0.067 & $-0.187^{* *}$ & -0.218 \\
No. of branches & $0.308^{*}$ & -0.030 & $-0.890^{* *}$ & 0.251 & 0.235 \\
Lodging (0-9) & $0.512^{* *}$ & 0.052 & $0.386^{* *}$ & $0.738^{* *}$ & 0.117 \\
Days to flowering & $0.752^{* *}$ & 0.085 & 0.116 & $-0.431^{* *}$ & 0.253 \\
Days to maturity & $0.633^{* *}$ & $0.565^{* *}$ & 0.130 & -0.155 & 0.245 \\
100-seed weight (g) & 0.155 & $0.860^{* *}$ & -0.201 & 0.012 & $-0.402^{* *}$ \\
\hline
\end{tabular}

${ }^{*},{ }^{* *}$ : Significantly difference at $5 \%$ and $1 \%$ level, respectively.

accounted for $71.6 \%$ of the total variance (Table 2).

Correlations between morphological markers and principle components were analyzed. Principal component 1 showed significant correlation with all morphological markers except 100-seed weight. Plant height and days to flowering among 7 characters were the largest contributors for classification (Table 3). Similar results were observed by Kim et al. (1999).

The scatter diagram was made with the first two principal components (Fig. 1). The relationship between morphological characters and tocopherol content of soybean seeds was considered. Group A was consisted of genotypes the high $\gamma$-tocopherol seeds and showed early flowering, short plant height and small seed weight. Group B was consisted of the seeds with high total tocopherol content, while group $\mathrm{C}$ was belonged to the high a-tocopherol seeds and late flowering, long plant height, many nodes and weak to lodging.

Among 56 soybean genotypes content of a-tocopherol was highest in Tanner as $33.6 \mu \mathrm{g} / \mathrm{g}$, while that of $\gamma$-tocopherol in PI 91073 as $195.6 \mu \mathrm{g} / \mathrm{g}$. Content of $\delta$-tocopherol was highest in IT 105622 as $29.8 \mu \mathrm{g}$ (Table 4). $\delta$-Tocopherol

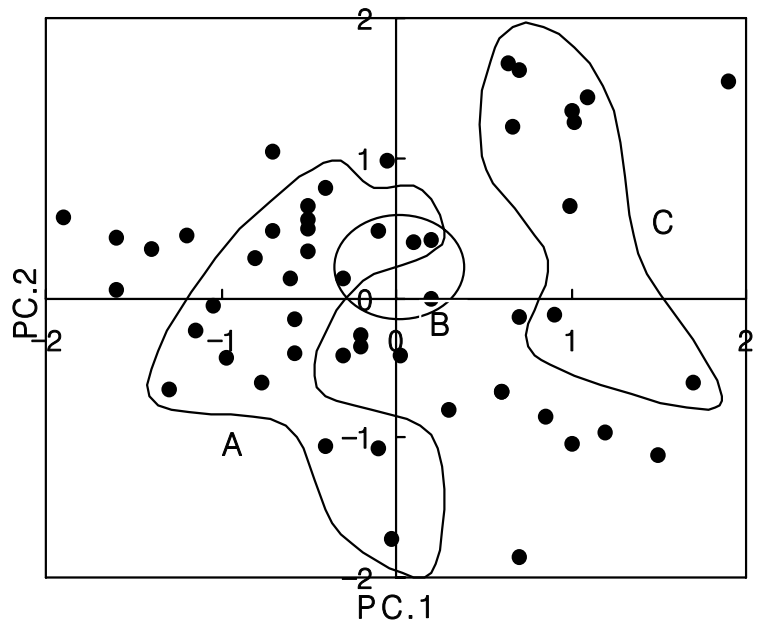

Fig. 1. Scatter diagram of 56 soybean germplasms by the first two principal components. A, high $\gamma$-tocopherol varieties; $\mathrm{B}$, high total tocopherol varieties; $\mathrm{C}$, high a-tocopherol varieties.

is synthesized at the earliest of biosynthesis pathway and a-tocopherol is a final type at the process of biosynthesis in plant. An increase in a-tocopherol is generally associated with improved stress tolerance especially, protection against water deficit (Moran et al., 1994), UV-B radiation (DeLong \& Steffen 1997), salt stress (Gossett et al., 1994), chilling 
Table 4. Tocopherol contents in seeds of 56 soybean genotypes.

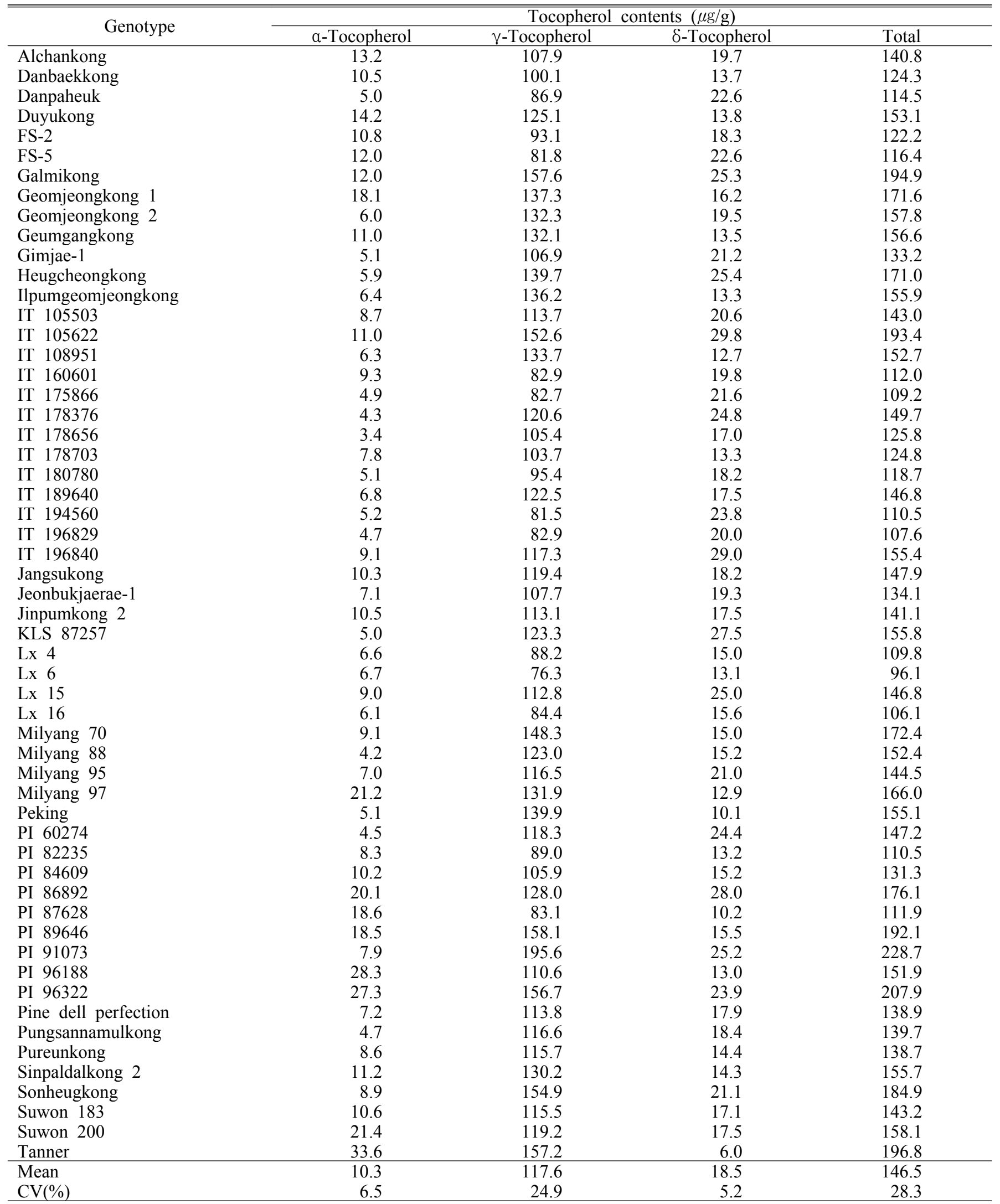


(Leipner et al., 1999) and pollutants (Schmieden \& Wild, 1994).

Tocopherol compositions in developing seeds was determined in PI 96322 and Alchankong. The contents of tocopherol were gradually increased till 10 days before maturity in the two genotypes. After the peak, they were slightly decreased (Fig. 2).

The tocopherol contents of seeds grown at the early seeding date (May 26) were higher than those grown at the late seeding date (June 28). And the total tocopherol contents of seeds harvested in Gimje were higher than those in Iksan at the same seeding date except PI 96322 (Fig. 3)

However, no significant difference was found between Iksan and Gimje in $\delta$-tocopherol. The results suggested that the content of tocopherol in soybean seed be affected by seeding dates and growth locations. However, we did not know which one was the attribution factor either climate or soil condition affecting tocopherol contents in soybean seeds.
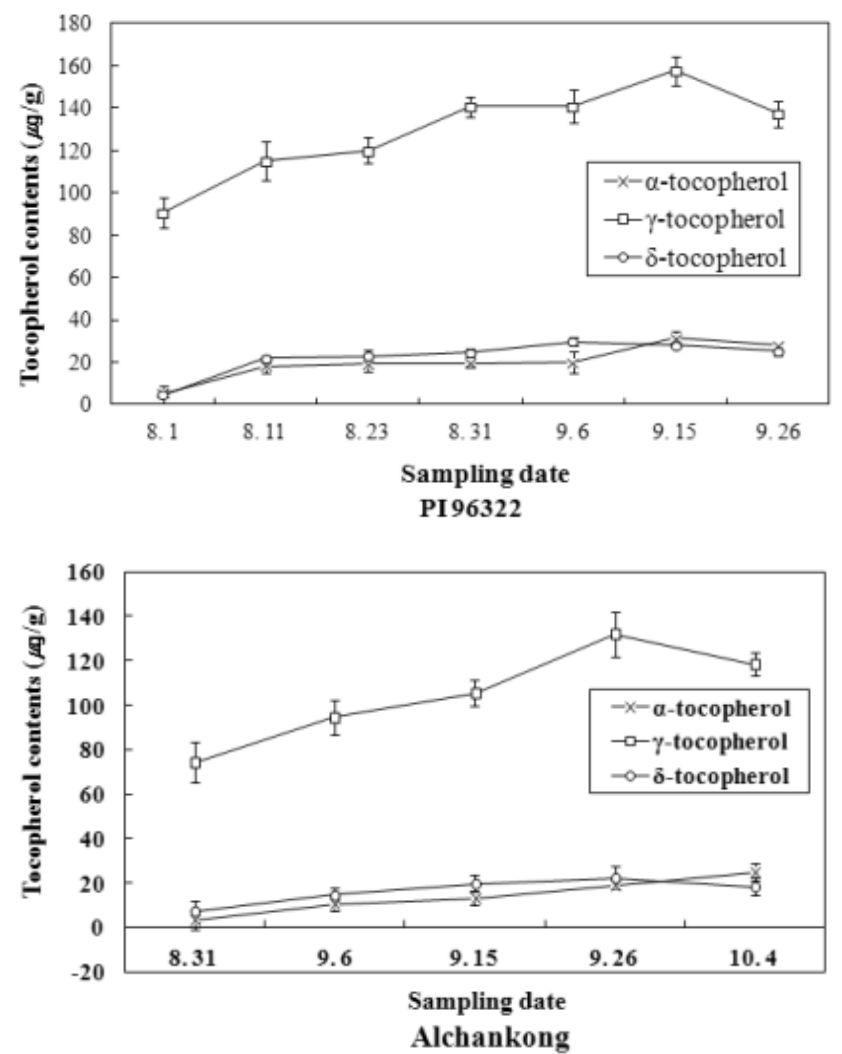

Fig. 2. Changes of tocopherols in developing soybean seeds.
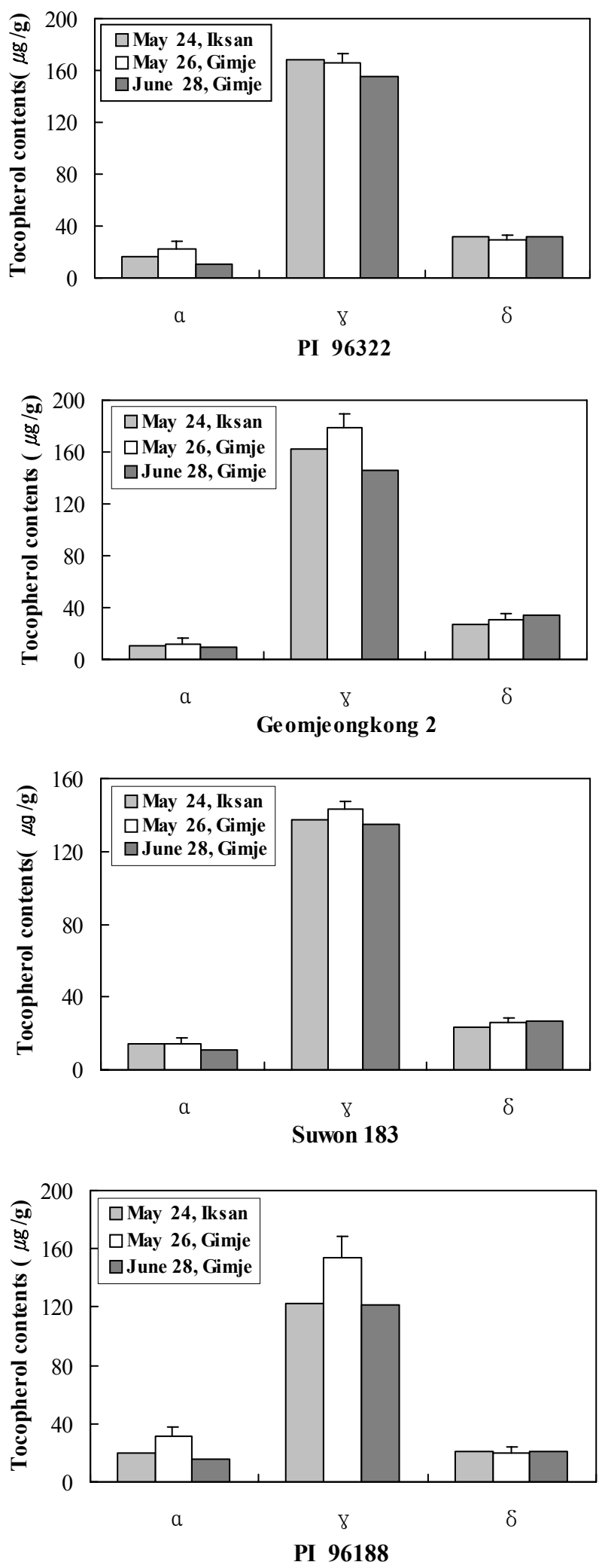

Fig. 3. Contents of tocopherols in mature seeds grown at different seeding dates and locations. Vertical bar indicates LSD values at 5\% level. 


\section{REFERENCES}

Carpenter A. P. 1979. Determination of tocopherols in vegetable oils. J. Am. Oil Chem. Soc. 56 : 668.

DellaPenna, D. 2005. Progress in the dissection and manipulation of vitamin E synthesis. Trends Plant Sci. 10 : 574-579.

DeLong J. M., and K. L. Steffen. 1997. Photosynthetic function, lipid peroxidation and a-tocopherol content in spinach leaves during exposure to UV-B radiation. Can. J. Plant Sci. 77 : 453-459.

Fukuzawa K., A. Tokumura, S. Ouchi, and H. Tsukatani. 1982. Antioxidant activities of tocopherols on $\mathrm{Fe}^{2+}$-ascorbate-induced lipid peroxidation in lecithin liposomes. Lipids. 17 : 511-513.

Gossett D. R., E. P. Millhollon, and M. C. Lucas. 1994. Antioxidant response to $\mathrm{NaCl}$ stress in salt-tolerant and salt-sensitive cultivars of cotton. Crop Sci. 34 : 706-714.

Hirschberg J. 1999. Production of high-value compounds: carotenoids and vitamin E. Curr. Opin. Biotech. 10 : 186-191.

Kamal-Eldin A., and L. A. Appelqvist. 1996. The chemistry and antioxidant properties of tocopherols and tocotreinols. Lipids $31:$ 671-701.

Kim Y. J., S. K. Suh, H. S. Kim, H. K. Park, and M. S. Park. 1999. Classification of soybean accessions by morphological characteristics. Kor. J. Breed. 31(2) : 132-137.

Kim Y. J., S. J. Yun, H. K. Park, M. S. Park, and S. Y. Cho. 1997. Phylogenetic relationship analyses of soybean accessions by morphological and RAPD markers. Society for the Advancement of Breeding Researches in Asia and Oceania (SABRAO), 8th Congress Proceedings pp. 179-180.

Korea Nutrition Society (KNS). 2000. Korean recommended daily allowance of nutrients.

Kwon T. W., and H. G. Brown. 1984. Oxidatives stability of soybean oil at different stages of refining. J. Am. Oil Chem. Soc. 61 : 18-43.

Leipner J., Y. Fracheboud, and P. Atamp. 1999. Effect of growing season on the photosynthetic apparatus and leaf antioxidative defenses in two maize genotypes of different chilling tolerance. Environ. Exp. Bot. 42 : 129-139.

Moran, J. F., M. Becana, I. Iturbe-Ormaetxe, S. Frechilla, R. V. Klucas, and P. Aparicio-Tejo. 1994. Drought induces oxidative stress in pea plants. Planta 194 : 346-352.

Munné-Bosch S., and L. Alegre. 2002. The function of tocopherols and tocotrienols in plants. Critical Reviews in Plant Sci. 21(1) : 31-57.

Pryor W. A. 2000. Free Radic. Biol. Med. 28 : 141-164.

Schmieden U., and A. Wild. 1994. Changes in levels of alphatocopherol and ascorbate in spruce needles at three low mountain sites exposed to $\mathrm{Mg}^{2+}$-deficiency and ozone. $\mathrm{Z}$. Naturforsch. 49c : 171-180.

Sheppard A. J., and A. T. Pennington. 1993. In Vitamin E in health and disease (Packer L, Fuchs J eds.), Marcel Dekker, New York, NY. pp. 9-31.

Speek A. J., J. Schrijver, and W. H. P. Schreurs. 1985. Vitamin E composition of some seed oils and as determined by high-performance liquid chromatography with fluorometric detection. J. Food Sci. 50 : 121-124.

Traber MG, and H. Sies. 1996. Vitamin E in humans: demand and delivery. Annu. Rev. Nutr. 16 : 321-347.

Wolfgang M. M. 1976. Rapid method for the quantitative determination of individual tocopherols in oils and fats. J. Am. Oil Chem. Soc. 53 : 732-736.

World Cancer Research Fund (WCRF). 1997. Food, nutrition and the prevention of cancer: A global perspective, American Institute for Cancer Research. 